\title{
Gastric peroral endoscopic myotomy for transthyretin amyloidosis gastroparesis
}

Hereditary transthyretin amyloidosis is associated with gastrointestinal symptoms which can have a negative impact on quality of life [1], with gastroparesis being a frequent complication of familial amyloidotic polyneuropathy (FAP) [2]. Interventions that target symptoms while liver transplantation is awaited can be of the utmost importance for improvement of nutritional status and optimization of surgical outcomes. Gastric peroral endoscopic myotomy (G-POEM) has been described as safe with high technical and clinical success rates, mainly for postoperative, diabetic, and idiopathic gastroparesis [3].

A 38-year-old man with a genetic diagnosis of FAP and a 10-year history of neuropathic manifestations who was receiving treatment with tafamidis presented with nausea, vomiting, post-prandial epigastric pain, and weight loss, with severe
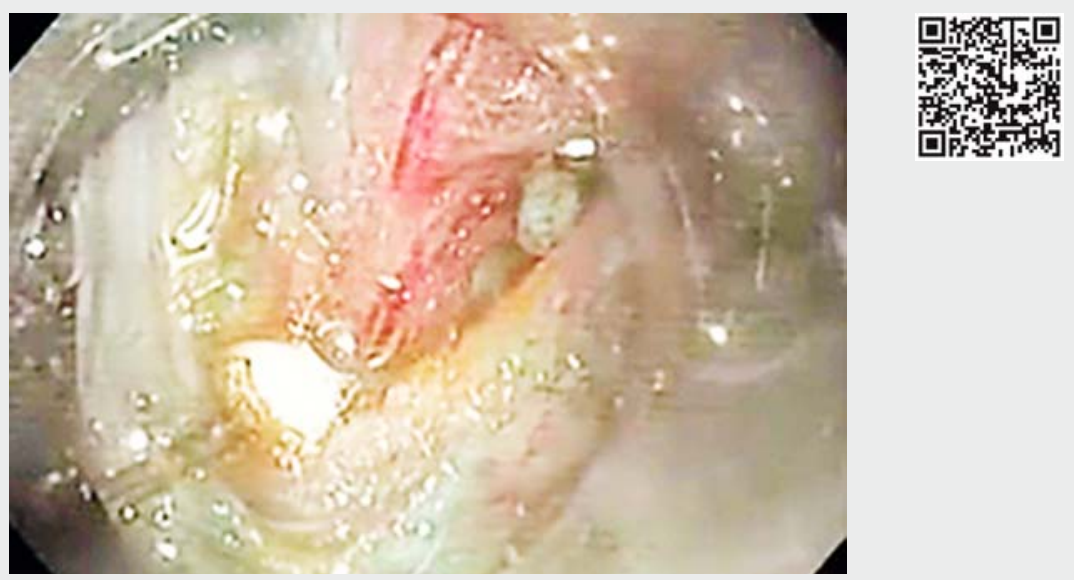

$\checkmark$ Video 1 A gastric peroral endoscopic myotomy (G-POEM) procedure is performed for amyloidotic gastroparesis, with the following steps: mucosotomy, submucosal dissection, submucosal tunneling, coagulation of the submucosal $(\mathrm{Sm})$ vessels, identification of the pyloric arch, IT knife anchoring at the pyloric arch, creation of the pyloromyotomy, and closure of the mucosal defect with endoclips.
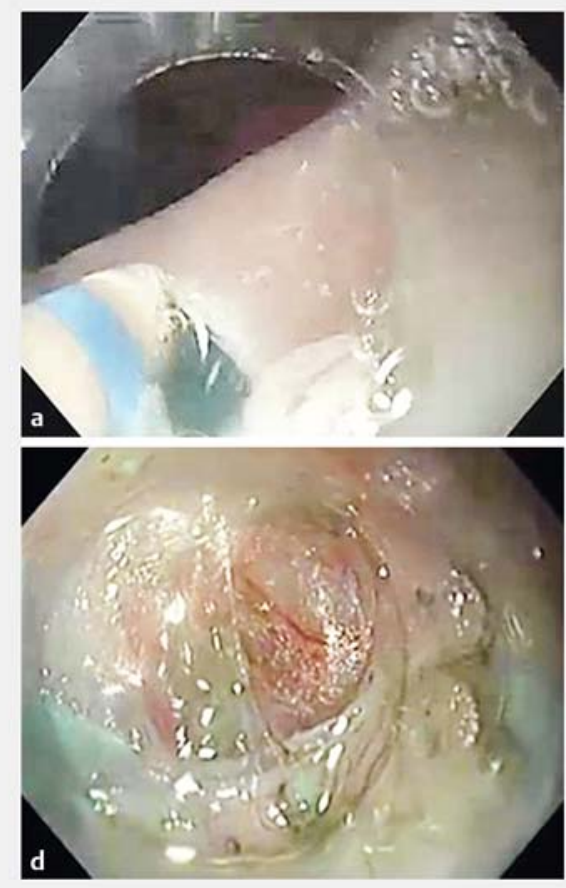
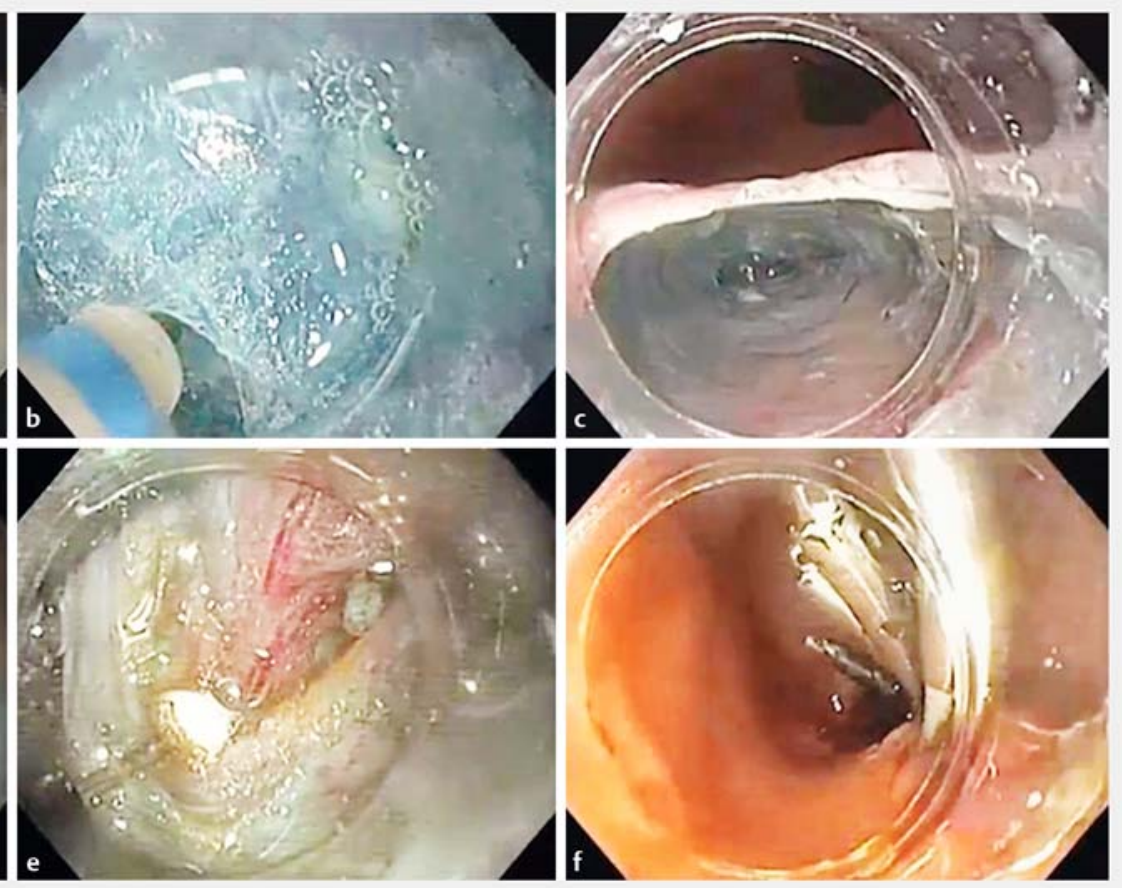

- Fig. 1 Endoscopic images showing: a the mucosotomy performed on the greater curvature of the antrum; $\mathbf{b}$ submucosal dissection being performed; $\mathbf{c}$ creation of a submucosal tunnel; $\mathbf{d}$ identification of the pyloric arch; e creation of a 2-cm pyloromyotomy; $\mathbf{f}$ the mucosal defect after closure with endoclips. 
gastroparesis on gastric emptying scintigraphy (GES; $\mathrm{T}_{50}$ of $50 \%$ at $120 \mathrm{~min}$ utes). He was started on combined prokinetic and antiemetic therapy, which was further optimized to maximum tolerated doses. Because of his continuing symptoms, with a Gastroparesis Cardinal Symptom Index (GCSI) of 26 points, and malnutrition risk, with a net weight loss of $20 \mathrm{~kg}$ over 2 years, G-POEM was proposed to the patient.

The procedure ( $\triangleright$ Video 1 ) followed the overall steps previously described [4]. A submucosal injection was performed on the greater curvature of the antrum, proximal to the pylorus, with a subsequent mucosotomy ( $>$ Fig. 1 a) and submucosal tunneling dissection using a

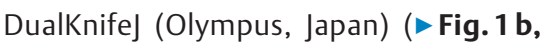
c). After identification of the pyloric arch ( Fig. $1 \mathrm{~d})$, a pyloromyotomy $(2 \mathrm{~cm}$ in length) was created with an ITknife2 (Olympus) ( $\triangleright$ Fig.1e). The mucosal defect was then closed using endoclips ( Fig.1f). After 24 hours, an esophagogastroduodenography showed normal emptying of contrast into the duodenum, after which oral intake was resumed with no complications.

The patient continues to wait for a liver transplant but, 6 months later, he denies nausea and vomiting, tolerates normalsized meals without using prokinetics, and scores 6 points on GCSI, with a $T_{50}$ of $44 \%$ at 120 minutes on GES.

G-POEM seems feasible, beneficial, and safe in this particular subset of patients with gastroparesis.

Endoscopy_UCTN_Code_TTT_1AO_2AJ
Competing interests

None

The authors

Tiago P. Guedes, Ricardo Küttner-Magalhães, Luis Maia, João Sousa, Mónica Garrido, Isabel Pedroto

Gastroenterology Department, Porto Hospital Centre, Porto, Portugal

\section{Corresponding author}

Tiago P. Guedes, MD

Gastroenterology Department, Porto Hospital Centre, Porto, Portugal

tiagoapguedes@gmail.com

\section{References}

[1] Mundayat R, Karayal ON, Anan I et al. THAOS: Gastrointestinal manifestations of transthyretin amyloidosis-common complications of a rare disease. Orphanet J Rare Dis 2014; 9: 61

[2] Suhr OB, Anan I, Åhlström KR et al. Gastric emptying before and after liver transplantation for familial amyloidotic polyneuropathy, Portuguese type [Val30Met]. Amyloid 2003; 10: $121-126$

[3] Khoury T, Mizrahi M, Mahamid M et al. A state of the art review with literature summary on gastric per-oral endoscopic pyloromyotomy for gastroparesis. J Gastroenterol Hepatol 2018; 33: 1829-1833

[4] Gonzalez J-M, Vanbiervliet G, Vitton V et al. First European human gastric peroral endoscopic myotomy, for treatment of refractory gastroparesis. Endoscopy 2015; 47 (Suppl. 01): E135-E136
Bibliography

DOI https://doi.org/10.1055/a-0826-9166

Published online: 21.2.2019

Endoscopy 2019; 51: E101-E102

(c) Georg Thieme Verlag KG

Stuttgart · New York

ISSN 0013-726X

\section{ENDOSCOPY E-VIDEOS}

https://eref.thieme.de/e-videos

口回 Endoscopy E-Videos is a free Fection, reporting 田: on interesting cases and new techniques in gastroenterological endoscopy. All papers include a high quality video and all contributions are freely accessible online.

This section has its own submission website at https://mc.manuscriptcentral.com/e-videos 